\title{
Increased serum osteocalcin levels in patients with paraplegia
}

\author{
P Pietschmann, ${ }^{1}$ P Pils, ${ }^{2}$ W Woloszczuk,${ }^{3}$ R Maerk, ${ }^{3}$ D Lessan, ${ }^{3} \mathrm{~J} \mathrm{Stipicic}^{3}$ \\ ${ }^{1}$ Department of Medicine II, University of Vienna; ${ }^{2}$ Spinal Cord Rehabilitation Center, \\ Weisser Hof, AUVA, A-3400 Klosterneuburg, Austria; ${ }^{3}$ Ludwig Boltzmann Institute for \\ Clinical Endocrinology, Vienna, Austria.
}

\begin{abstract}
Osteocalcin $(\mathrm{OC})$ is a specific serum parameter of bone formation. Since bone metabolism disturbances, including osteoporosis, are seen in paraplegia, the serum levels of $\mathrm{OC}$, midregional parathyroid hormone $(\mathrm{mPTH})$, intact parathyroid hormone (iPTH) and calcitonin (CT) serum levels were determined in 13 patients with paraplegia or tetraplegia and 15 control subjects by radioimmunoassay in a cross sectional study. In addition, the urinary hydroxyproline/creatine and the urinary calcium/creatinine ratio was determined. Serum OC levels were significantly increased in the patients with spinal cord injury $(p<0.02)$, whereas serum levels of $\mathrm{mPTH}$, iPTH and CT were not statistically different.

The urinary hydroxproline/creatinine ratio was significantly higher in the patients than in the controls $(p<0.02)$, and the urinary calcium/creatinine ratio also tended to be higher in the patients. In a follow up study over 6 months after spinal cord injury, serum OC, serum iPTH, urinary hydroxyproline/creatinine ratio and the calcium/creatinine ratio were determined in 6 patients at monthly intervals. Hyperhydroxyprolinuria preceded the gradual increase of serum OC from normal to clearly elevated levels. Our data suggest that increased bone resorption in paraplegia is linked to an enhanced osteoblastic activity.
\end{abstract}

Key words: osteocalcin-bone GLA protein; paraplegia; tetraplegia; bone turnover.

\section{Introduction}

Alterations in bone metabolism including osteoporosis, hypercalciuria and an increased hydroxyproline excretion are frequent findings in patients with spinal cord injuries. ${ }^{1-4}$ Periarticular ossification and urinary tract stone formation reflecting disturbed calcium homeostasis can present major clinical problems delaying rehabilitation.

Osteocalcin (OC, bone gla-protein) is a 49-amino acid protein, which is synthesised by the osteoblasts and can be measured in the peripheral blood by radioimmunoassay. ${ }^{5}$ Serum levels of OC have been found to be a specific noninvasive parameter of osteoblast activity and bone formation in various endocrine disorders, postmeno-

*Correspondence: Dr P Pils. pausal osteoporosis and normal subjects as well. ${ }^{6-8}$

In order to gain further insight into bone metabolism alterations following spinal cord injury, it was of interest to determine serum-OC levels in paraplegic and intetraplegic patients, both in a cross sectional and a follow up study design.

\section{Subjects and methods}

\section{Cross sectional study}

Thirteen male patients (mean age $30.5+6.1$ years) with complete paraplegia or tetraplegia $(\mathrm{C} 4-\mathrm{Ll}) 4$ to 812 weeks (median 61.5 weeks) after traumatic spinal cord injury were studied. All patients were previously healthy. Routine blood chemistry including plasma calcium, plasma phosphorus levels, liver and renal function tests was normal in subjects. All but one patient had vertebral luxation or fracture and only one patient 
had polytrauma (46 weeks previously). All patients fed by mouth and had no special diet. Recently injured patients were treated with bedrest. Full time wheel chair mobilisation was achieved in all subjects within a period of 2 to 4 months after injury, depending on the level of spinal cord lesion.

\section{Follow up study}

Six male patients (mean age 31.1 years, range 18-51) were selected according to the following criteria: (1) the previously healthy patients had been admitted to the Rehabilitation Center within one month after the traumatic spinal cord injury; (2) no other relevant bony lesions were present. All 6 patients had complete paraplegia or tetraplegia on admission (C5, C7, T5, T10, T12, L2). One patient (L2) recovered from paraplegia 4 months after injury; the data obtained from this paraparetic patient after recovering were excluded from the analysis. Blood samples were taken at monthly intervals begining one month after the accident, for a follow up period of 6 months. For technical reasons 2 blood samples were missing in one patient (T5).

Controls: blood parameters were studied in 15 healthy male volunteers, mean age $32.1+4.7$ years and urine samples were provided from 8 of them.

\section{Methods}

Blood samples were obtained at 08.00 hours from all patients and control subjects after an overnight fast.

Serum levels of osteocalcin (OC) were determined using a radioimmunoassay kit manufactured by CIS International (Gif sur Yvette, France) as previously described ${ }^{7}$ and serum calcitonin (CT) was measured using a RIA kit purchased from ImmunoNuclear (Stillwater, USA). Serum PTH was measured both by a RIA with midregion specificity using synthetic human PTH(43-68) as tracer and standard, mPTH (Sorin Biomedica, Milano, Italia) and a RIA specific for the intact PTH molecule, iPTH (Nichols Institute, San Juan Capistrano, CA, USA). ${ }^{9}$ All RIAs had intraassay coefficients of variance in the useful range of the assay less than $8 \%$ and interas- say coefficients less than $14 \%$. The minimal detectable concentration of $\mathrm{OC}$ was $0.2 \mathrm{ng} / \mathrm{ml}$; that of $\mathrm{mPTH} 20 \mathrm{pmol} / \mathrm{l}$; that of iPTH $2 \mathrm{pg} / \mathrm{ml}$ and that of CT $13 \mathrm{pg} / \mathrm{ml}$.

In the follow up study serum levels of $\mathrm{OC}$ and $\mathrm{iPTH}$ were determined as described above.

Urine samples were obtained from patients and control subjects after an overnight fast. A 3-hour collecting period from 06.00 to 09.00 hours was chosen in the present study for the convenience of patients and controls. Urine was collected either by a suprapubic catheter, intermittent catheterisation or by reflex voiding followed by a single catheterisation in order to empty the bladder completely. In the literature a very close correlation between the postabsorptive hydroxyproline/creatinine ratio and the 24-hour hydroxyproline excretion has been described. ${ }^{10}$

Hydroxyproline (HYPRO) concentration in the 3-hour fasting urine was determined by strong acid cation exchange resin (Hypronosticon, Organon Teknika, Boxta, Netherlands) ${ }^{11}$ and the HYPRO/creatinine ratio was calculated. ${ }^{10}$

Urinary calcium concentration in the 3-hour fasting urine was determined using a standard colorimetric procedure (Astra4, Beckman Instruments, USA), and the urinary calcium/creatinine ratio was calculated. ${ }^{12}$

In the follow up study urinary samples were obtained as described above at monthly intervals over a period of 5 months.

\section{Statistics}

In order to compare the patients' group of the cross sectional study with their controls the Wilcoxon 2 sample test and the KruskalWallis test were used. To refute Ho (no difference between the two groups) an error probability of less than $2 \%$ was assumed, even when $p$ values were lower.

In order to correlate the duration of paraplegia with the parameters of bone metabolism in the cross sectional study the Kendall Tau correlation coefficient was used.

Unless otherwise indicated data in the text and the tables are given as mean + SD. 


\section{Results}

Cross sectional study

Serum levels of OC, mPTH, iPTH and CT in the 13 patients with paraplegia or tetraplegia and the controls are shown in Table I. Serum OC levels were significantly increased $(p<0.02)$ in the patients when compared with the controls. Serum mPTH and CT levels in the patients were not statistically different from the control group. Mean iPTH values were somewhat lower in the whole group of paraplegic and tetraplegic patients, but did not differ significantly. The urinary HYPRO/creatinine ratio was significantly higher in the patients with paraplegia or tetraplegia than in the control subjects $(p<0.02)$ and urinary calcium/creatinine ratio was also higher in the patients than in the controls; however the differences did not reach statistical significance (Table II).

When the patients were subdivided into paraplegic and tetraplegic groups the biochemical bone metabolism parameters were similar (Table III).

When the paraplegic and tetraplegic patients were subdivided into those studied less than and into those studied more than one year after spinal cord injury, serum iPTH levels were higher and the HYPRO/creatinine ratio was lower in the patients with longterm disease (Table IV).

In the whole group of patients a significant positive correlation between the duration of paraplegia and serum iPTH levels (tau $=0.56, p<0.01)$ but not with OC $(\operatorname{tau}=-0.11), \quad \operatorname{mPTH}(\operatorname{tau}=0.20), \quad \mathrm{CT}$

Table I Serum levels of osteocalcin (OC), midregional parathyroid hormone (mPTH), intact parathyroid hormone (iPTH) and calcitonin in 13 patients with paraplegia or tetraplegia (PAT) and 15 control subjects $(\mathrm{CO})$

\begin{tabular}{lcccc}
\hline & & PAT & CO & \\
\hline OC & $(\mathrm{ng} / \mathrm{ml})$ & $10.5 \pm 3.3$ & $7.5 \pm 2.3$ & $p<0.02$ \\
mPTH & $(\mathrm{pmol} / \mathrm{l})$ & $61.5 \pm 33.0$ & $77.5 \pm 34.1$ & n.s. \\
iPTH & $(\mathrm{pg} / \mathrm{ml})$ & $22.8 \pm 10.9$ & $27.9 \pm 10.5$ & n.s. \\
CT & $(\mathrm{pg} / \mathrm{ml})$ & $48.3 \pm 14.8$ & $56.3 \pm 14.4$ & n.s. \\
\hline
\end{tabular}

Table II Urinary calcium/creatinine ratio and hydroxyproline (HYPRO)/creatinine ratio in 13 paraplegic or tetraplegic patients (PAT) and 8 control subjects $(\mathrm{CO})$

\begin{tabular}{lcccc}
\hline & Calcium $(\mathrm{mg})$ creatinine $(\mathrm{mg})$ & HYPRO $(\mathrm{mg})$ creatinine $(\mathrm{mg})$ & $\cdot 100$ \\
\hline PAT & $0.44 \pm 1.04$ & n.s. & $4.71 \pm 3.44$ & $p<0.02$ \\
CO & $0.10 \pm 0.08$ & $1.63 \pm 0.44$ & \\
\hline
\end{tabular}

Table III Serum osteocalcin (OC), intact parathyroid hormone (iPTH), midregional parathyroid hormone $(\mathrm{mPTH})$, calcitonin $(\mathrm{CT})$ and urinary calcium/creatinine ratio, hydroxyproline (HYPRO)/ creatinine ratio in 7 paraplegic (PARA) and 6 tetraplegic (TETRA) patients

\begin{tabular}{lccc} 
& PARA $(n=7)$ & TETRA $(n=6)$ & \\
\hline OC $(\mathrm{ng} / \mathrm{ml})$ & $10.6 \pm 3.6$ & $10.3 \pm 3.2$ & n.s. \\
iPTH $(\mathrm{pg} / \mathrm{ml})$ & $23.9 \pm 11.8$ & $21.6 \pm 10.7$ & n.s. \\
mPTH $(\mathrm{pmol} / \mathrm{l})$ & $67.2 \pm 44.4$ & $54.8 \pm 12.4$ & n.s. \\
CT $(\mathrm{pg} / \mathrm{ml})$ & $53.3 \pm 16$ & $42.5 \pm 10.8$ & n.s. \\
calcium $(\mathrm{mg}) /$ creatinine $(\mathrm{mg})$ & $0.66 \pm 1.43$ & $0.18 \pm 0.13$ & n.s. \\
HYPRO $(\mathrm{mg}) /$ creatinine $(\mathrm{mg}) \cdot 100$ & $4.76 \pm 3.86$ & $4.65 \pm 1.33$ & n.s. \\
\hline
\end{tabular}


$(\operatorname{tau}=-0.23)$ and the urinary calcium/creatinine ratio (tau $=-0.42$ ) could be found. Urinary HYPRO/creatinine ratio correlated negatively with the duration of disease $(\mathrm{tau}=-0.69, p<0.002)$.

\section{Follow up study}

The serum levels of OC, iPTH and the urinary HYPRO/creatinine and calcium/ creatinine ratio are shown in Figures 1 and 2. One month after the spinal cord injury serum OC levels were normal; subsequently a continuous increase to levels considerably above the normal range was observed. Serum iPTH-levels were lowest one to 4 months after the injury and tended to increase thereafter.

Urinary HYPRO/creatinine ratio was always manifold higher than in the controls. Urinary calcium/creatinine ratio during the entire follow up period was at least threefold higher than the mean control value.

\section{Discussion}

The data of the cross-sectional study demonstrate increased serum osteocalcin and increased urinary hydroxyproline excretion in patients with paraplegia or tetraplegia. In the follow up study serum OC levels were normal one month after injury, but increased continuously thereafter. In contrast to the OC levels urinary HYPRO/creatinine ratio was already increased at the beginning of the follow up study.

Our data of an elevated hydroxyproline

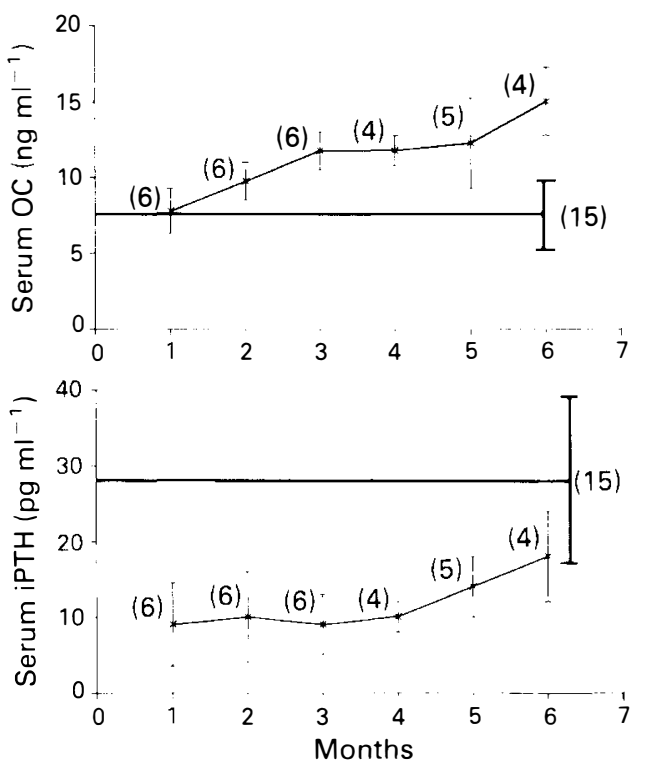

Figure 1 Serum osteocalcin (OC) and serum intakt parathyroid hormone (iPTH) in the paraplegic or tetraplegic patients. $(n)=$ number of patients; the thick horizontal bars indicate the values of the control subjects. The data are given as the mean $\pm \mathrm{SD}$.

excretion in paraplegia, which is in accordance with the literature, ${ }^{4,13}$ indicates an increased bone resorption in the patients studied. Furthermore, the follow up study demonstrates that bone resorption (ie hyperhydroxyprolinuria) precedes the increase of osteoblastic activity (ie hyperosteocalcinaemia). Thus bone metabolism in the patients studied might resemble the

Table IV Serum osteocalcin (OC), intact parathyroid hormone (iPTH), midregional parathyroid hormone $(\mathrm{mPTH})$, calcitonin $(\mathrm{CT})$ and urinary calcium/creatinine ratio, hydroxyproline (HYPRO)/creatinine ratio in 6 paraplegic or tetraplegic patients within one year after spinal injury (RECENT) and in 7 paraplegic or tetraplegic patients one to 15 years after spinal injury (LONGTERM)

\begin{tabular}{lccc} 
& Recent $(n=6)$ & Longterm $(n=7)$ & \\
\hline OC $(\mathrm{ng} / \mathrm{ml})$ & $10.4 \pm 3.2$ & $10.6 \pm 3.6$ & n.s. \\
iPTH $(\mathrm{pg} / \mathrm{ml})$ & $16.0 \pm 11.3$ & $28.7 \pm 6.5$ & $p<0.05$ \\
mPTH $(\mathrm{pmol} / \mathrm{l})$ & $51.7 \pm 29.4$ & $69.9 \pm 35.8$ & n.s. \\
CT $(\mathrm{pg} / \mathrm{ml})$ & $51.1 \pm 11.1$ & $45.9 \pm 17.9$ & n.s. \\
calcium $(\mathrm{mg}) / \mathrm{creatinine}(\mathrm{mg})$ & $0.8 \pm 1.5$ & $0.11 \pm 0.04$ & n.s. \\
HYPRO $(\mathrm{mg}) / \mathrm{creatinine}(\mathrm{mg}) \cdot 100$ & $7.25 \pm 3.6$ & $2.5 \pm 0.8$ & $p<0.02$ \\
\hline
\end{tabular}




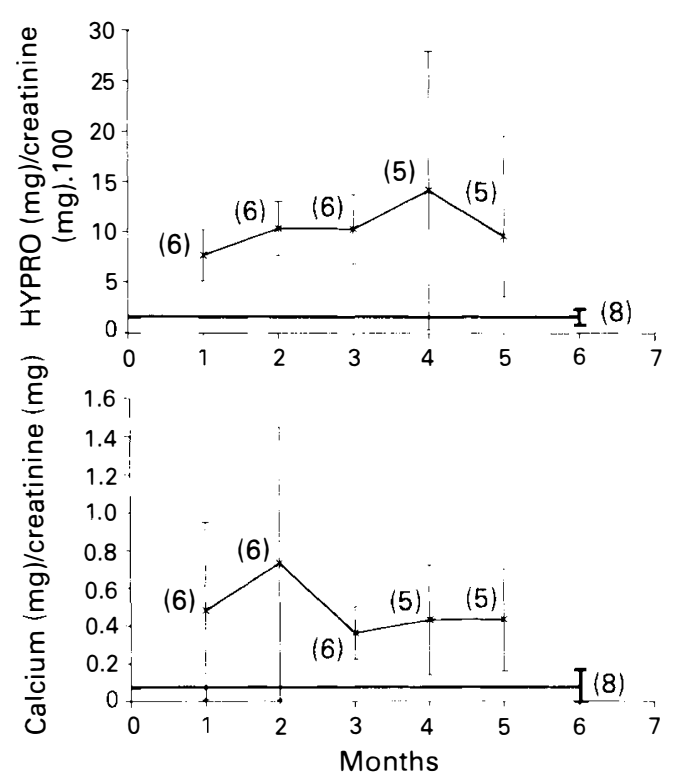

Figure 2 Urinary hydroxyproline (HYPRO)/ creatinine $\cdot 100$ ratio and urinary calcium/ creatinine ratio in the paraplegic or tetraplegic patients. $(n)=$ number of patients; the thick horizontal bars indicate the values of the control subjects. The data are given as the mean \pm SD.

high turnover model of postmenopausal osteoporosis, where an accelerated bone resorption exceeds the increased bone formation. The serum levels of iPTH which are considered to represent the biologically active PTH seemed suppressed in the early period after the injury but showed a tendency to increase after 6 months in accord- ance with the positive correlation between the serum iPTH levels and the duration of paraplegia in the cross sectional study.

The urinary calcium/creatinine ratio was at least threefold higher in the halfyear follow up period after spinal cord injury than the mean control value; similarily in the cross sectional study urinary calcium excretion was higher in the patients than in the controls. These data are in accordance with Stewart et al who found low PTH levels and hypercalciuria in paraplegia. ${ }^{14}$ Obviously, the changes in bone resorption of our patients are more pronounced than in healthy immobilised subjects ${ }^{15}$ and it should be stressed that despite mobilisation of the paraplegic nad tetraplegic patients the lack of muscle activity on the skeletal system may enhance bone depletion.

In conclusion, the increased bone resorption in paraplegic patients is followed by an increase of serum osteocalcin demonstrating an enhanced osteoblastic activity. Immobilisation and loss of muscular activity following acute spinal cord injury in previously healthy males thus lead to a severe deterioration of bone metabolism.

\section{Acknowledgements}

We are indebted to the staff of the Spinal Cord Rehabilitation Center for skilful help and for providing the healthy control subjects and to the technicians of the laboratories for assistance. The AUVA and its representatives, $\mathrm{H}$ Kristen, W Krösl, E Oder and W Thiel funded our project generously.

\section{References}

1 Claus-Walker J, Carter RE, Campos RJ, Spencer WA (1975) Hyper-calcemia in early traumatic quadriplegia. J Chron Dis 28: 81-90.

2 Chantraine A (1978) Actual concept of osteoporosis in paraplegia. Paraplegia 16: 51-58.

3 Steinberg FU, Birge SJ, Cooke NE (1978) Hypercalcaemia in adolescent tetraplegic patients: case report and review. Paraplegia 16: 60-67.

4 Chantraine A, Heynen G, Franchimont P (1979) Bone metabolism, parathyroid hormone and calcitonin in paraplegia. Calif Tiss Int 27: 199-204.

5 Price PA, Parthemore JG, Deftos LJ (1980) New biochemical marker for bone metabolism. Measurement by radioimmunoassay of bone GLA protein in the plasma of normal subjects and patients with bone disease. J Clin Invest 66: 878-883.

6 Garcia-Carrasco M, Gruson M, de Vernejoul MC, Denne A, Miravet L (1988) Osteocalcin and bone morphometric parameters in adults without bone disease. Calif Tiss Int 42: 13-17.

7 Brown JP, Delmas PD, Malaval L, Edouard C, Chapuy MC, Meunier PJ (1984) Serum bone GLA-protein: a specific marker for bone formation in postmenopausal osteoporosis. Lancet 1: 1091-1093.

8 Lukert BP, Higgins JC, Stoskopf MM (1986) Serum osteocalcin is increased in patients with hyperthyroidism and decreased in patients receiving glucocorticoids. J Clin Endocrinol Metab 62: 1056-1058.

9 Nussbaum SR, Zahradnik RJ, Lavigne JR, Brennan GL, Nozawa-Ung K, Kim LY, Kentmann HT, Wang 
CA, Potts JT, Segre GV (1988) Highly sensitive two site immunoradiometric assay of parathyrine and its clinical utility in evaluating patients with hypercalcemia. Clin Chem 33: 1364-1367.

10 Neill HB, Palmieri GM, Neely CL, McDonald MW (1981) Postabsorptive urinary hydroxyproline test in patients with metastatic bone disease from breast cancer. Arch Intern Med 141: 1471-1473.

11 Goverde BC, Veenkamp FJN (1972) Routine assay of total urinary hydroxyproline based on resin-catalysed hydrolysis. Clin Chim Acta 41 : 29-40.

12 Stepan JJ, Pospichal J, Presl J, Pacovsky V (1989) Prospective trial of ossein-hydroxyapatite compound in surgically induced postmenopausal women. Bone 10: 179-185.

13 Naftchi NE (1985) Alterations of neuroendocrine functions in spinal cord injury. Peptides 6 (suppl 1): 85-94.

14 Stewart AF, Adler M, Byers CM, Segre GV, Broadus AE (1982) Calcium homeostasis in immobilization: an example of resorptive hypercalciuria. $N$ Engl J Med 306: 1136-1140.

15 Arnaud SB, Schneider VS, Morey-Holton E (1986) Effects of inactivity on bone and calcium metabolism. In: Sandler H, Vernikos J, editors. Inactivity: Physiological Effects, Academic Press Inc: 49-76. 